\title{
Sequestration of Urea and Nonurea Solutes in Renal Tissues of Rats with Hereditary Hypothalamic Diabetes Insipidus: Effect of Vasopressin and Dehydration on the Countercurrent Mechanism*
}

\author{
Heinz Valtin $\dagger$ \\ (From the Department of Physiology, Dartmouth Medical School, Hanover, N.H.)
}

This study was prompted by three problems: 1 ) the role of vasopressin in the countercurrent mechanism for concentrating urine; 2 ) the effect of dehydration on this mechanism; and 3 ) the behavior of this mechanism in the absence of vasopressin when the body fluid volumes are contracted rather than expanded.

Although it is generally accepted that countercurrent systems in the renal medulla effect the concentration of urine, several questions about the operation of these systems remain unanswered (1). For example, it is not known whether vasopression enhances the sequestration of nonurea solutes in the medullary interstitium, either by increasing the reabsorption of sodium from the loops of Henle, by slowing medullary blood flow, or both. Levitin, Goodman, Pigeon, and Epstein demonstrated a progressive and significant increase in sequestered sodium within the renal papilla and medulla of dogs as vasopressin was superimposed on a water diuresis by intravenous infusion (2). Since they also found the enrichment of papillary and medullary sodium by infused ${ }^{22} \mathrm{Na}$ to be more rapid during water diuresis than during antidiuresis, they suggested that vasopressin may promote medullary sequestration of sodium by slowing medullary blood flow, not by increasing reabsorption of sodium from the ascending loops of Henle. In contrast, Jaenike has pre-

* Submitted for publication September 2, 1965; accepted November 26, 1965.

Supported by U. S. Public Health Service research grant AM-08469-GM from the National Institute of Arthritis and Metabolic Diseases.

$\dagger$ Address requests for reprints to Dr. Heinz Valtin, Dept. of Physiology, Dartmouth Medical School, Hanover, N. H. 03755.

U. S. Public Health Service Research Career Program Award 6-K3-GM-21,786 from the National Institute of General Medical Sciences. sented indirect evidence suggesting that vasopressin does not enhance the medullary sequestration of nonurea solute (3).

Although other investigators have reported similar studies $(4,5)$, there still is no agreement whether or not vasopressin promotes the medullary sequestration of sodium. The availability of rats with a genetic, apparently absolute, defect for synthesizing vasopressin (6) seemed to present an ideal opportunity for reinvestigating this problem. If vasopressin promotes the medullary sequestration of sodium, one might predict that rats with diabetes insipidus (D.I.) would have significantly less medullary and papillary sodium than normal rats of the same strain, and that this deficiency might be corrected when D.I. rats are treated with vasopressin. The first series of experiments was designed to test these predictions.

Disagreement also persists on the effect of dehydration on the composition of the renal medulla and papilla. At least two groups of investigators found sequestration of papillary sodium to be greater in hydropenic dogs than in dogs in water diuresis $(2,7)$. Jaenike's studies suggested that there was no difference (3). Saikia (8), on the other hand, reported the medullary content of sodium to be significantly greater in hydropenic than in water-loaded hamsters, but he could not detect this difference in rats. Because of the continuing disagreement, we also reinvestigated this question.

The demonstration that urine could be concentrated in the absence of vasopressin $(9,10)$ called attention to the importance of mechanisms other than changes in membrane permeability to the operation of the countercurrent system. Reduction in glomerular filtration rate (GFR) may be accompanied by concentration of urine when vasopressin is absent, and a reduction in medullary 


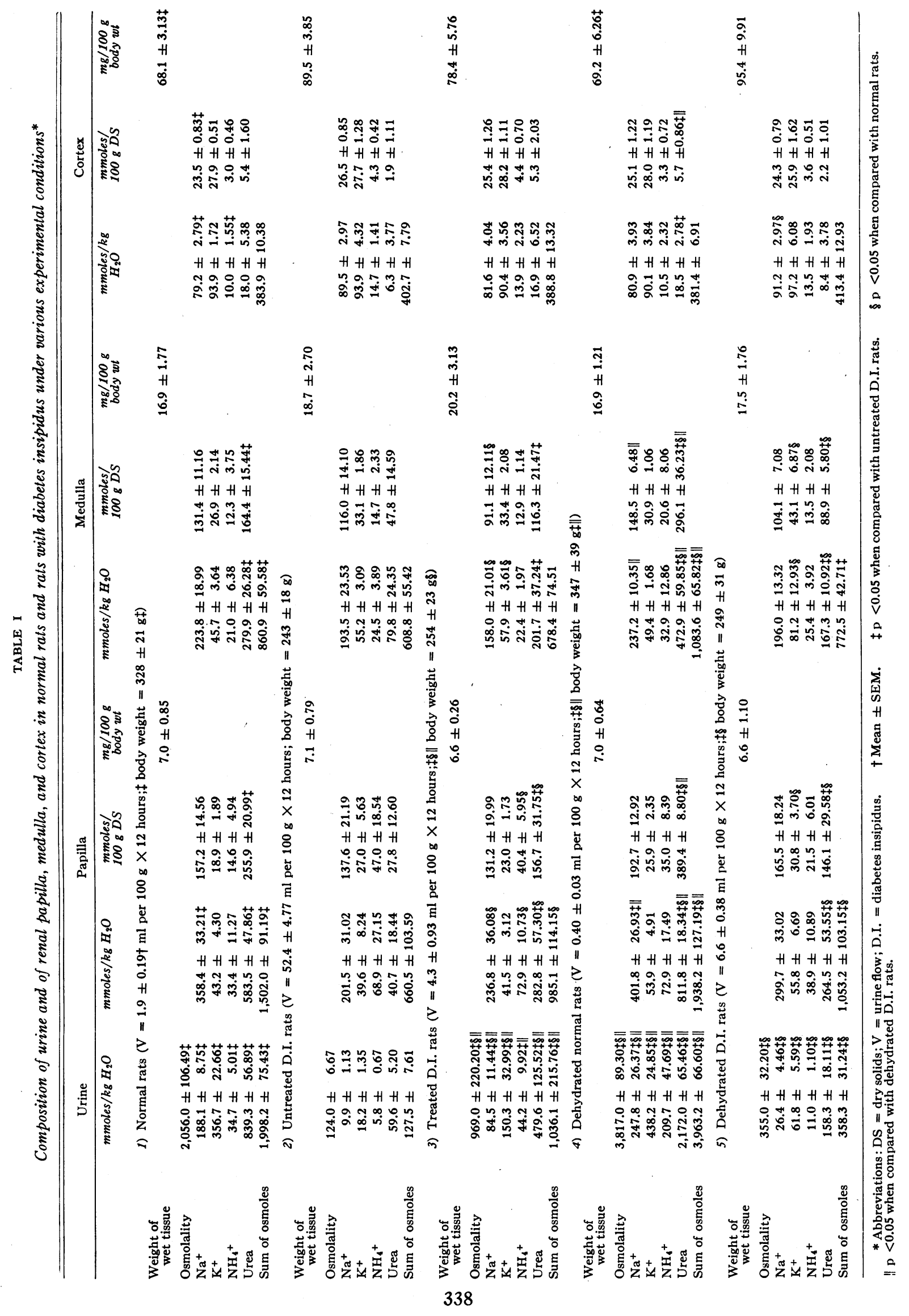


blood flow would be expected to have the same effect. In previous studies $(9,10)$ the experimental subjects were in acute water diuresis induced by large loads of hypotonic fluid. The urine, although hypertonic to the plasma, was only minimally concentrated. The observation that the urinary osmolality of D.I. rats deprived of drinking water for 24 hours could exceed 1,000 mOsm per $\mathrm{kg}$ (11) suggested that both papilla and urine could be concentrated greatly in the absence of vasopressin when the body fluid volumes were contracted rather than expanded. We therefore investigated this question by dehydrating D.I. rats.

\section{Methods}

Five groups of rats were tested: 1) normal rats of the Brattleboro strain (6), eating and drinking ad libitum (designated normal) ; 2) D.I. rats eating and drinking ad libitum (untreated D.I.) ; 3) D.I. rats given vasopressin, ${ }^{1} 1.0 \mathrm{U}$ subcutaneously, daily for 3 days immediately before sacrifice (treated D.I.); 4) normal rats deprived of drinking water, but not of food, for 2 days before sacrifice (dehydrated normal); and 5) D.I. rats deprived of drinking water, but not of food, during the 12 hours preceding sacrifice (dehydrated D.I.). All groups ate Purina Labena rat pellets. Each group consisted of 12 adult rats of both sexes, with a mean age of 8 months. Two rats of the same sex from any one group were tested simultaneously. The kidneys of one were used to determine water content, those of the other for chemical analysis. This procedure, rather than using the opposite kidney of the same rat for analyzing water content, was followed to get sufficient papillary tissue for chemical analysis.

During the period immediately preceding sacrifice, rats were kept in individual metabolism cages. This period lasted 12 hours for group 5 , and 18 hours for the other groups. Rats were then stunned by a blow to the head and killed by breaking the neck. The renal hilum was clamped with a hemostat, and the kidney removed and immersed, with clamp attached, in a 50:50 mixture of dry ice and acetone. The frozen kidney was then cut eccentrically so that the medulla and papilla remained with the larger portion. The papillary tip was cut off, weighed on a torsion balance to the nearest $0.1 \mathrm{mg}$, and then placed in a tissue grinder containing about $3 \mathrm{ml}$ of cold, doubly distilled water that had been measured accurately by weighing to the nearest $0.01 \mathrm{mg}$. Next, the inner medulla was shelled out and treated similarly. The renal capsule was then stripped off, and thin slices of outer cortex were pooled, weighed, and placed into an accurately measured volume of cold distilled water. Throughout these procedures the unprocessed tissues were kept frozen on dry ice. The tissues were then

1 Pitressin tannate in oil, Parke, Davis and Co., Detroit, Mich. ground by hand and the homogenates refrigerated until the chemical analyses had been completed.

Kidneys used for determining tissue water content also were removed after clamping the hilum, but they were not frozen in dry ice and acetone. Instead, they were quickly bisected, and the papillary tip was removed and placed in a preweighed test tube. The remaining tissue was then frozen on dry ice, and the samples of medulla and cortex were obtained as above. These samples were dried at $110^{\circ} \mathrm{F}$ for 1 week and weighed by tare to constant weight.

Sodium and potassium were measured with a Baird internal standard flame photometer, and $\mathrm{NH}_{4}{ }^{+}$and urea by the microdiffusion methods of Conway (12). Tissue osmolality was calculated at $2\left(\mathrm{Na}^{+}+\mathrm{K}^{+}+\mathrm{NH}_{4}^{+}\right)+$urea. Urinary osmolality also was calculated in this manner, and the result checked cryoscopically in a Fiske osmometer. The average water content of tissues from six rats in each group was used to convert the data to millimoles per kilogram of water and to millimoles per $100 \mathrm{~g}$ dry solid. Significance of the results was evaluated by Student's $t$ test (13).

\section{Results}

Normal vs. untreated and treated D.I. The data are presented in Table I. The severity of D.I. is reflected by a mean urine flow of more than $50 \%$ of body weight in 12 hours. After 3 days of therapy with large doses of exogenous vasopressin, the urinary volume in D.I. rats was decreased significantly, but not to normal (14). The significantly smaller body size in D.I. than in normal animals has been pointed out previously (6).

The urinary determinations show the good correspondence between the calculated and measured osmolalities. The three groups showed no significant differences in water content of cortical and medullary tissues (Figure 1), but the concentration of water in the papilla was significantly greater in untreated D.I. rats than in normals and treated D.I. animals. There was no significant difference in wet weights of medullary and papillary tissues when factored by body weight (Table I). Thus, approximately the same fractions of medulla and papilla were sampled.

Untreated D.I. rats, excreting urine with a mean osmolality of $124 \mathrm{mOsm}$ per $\mathrm{kg}$, had an average papillary osmolality of $661 \mathrm{mOsm}$ per kg. In normal animals these values were 2,056 and 1,502 , respectively. The disparity between the last two values presumably results from having to go down the osmotic gradient from papillary tip toward inner medulla to obtain sufficient sample 

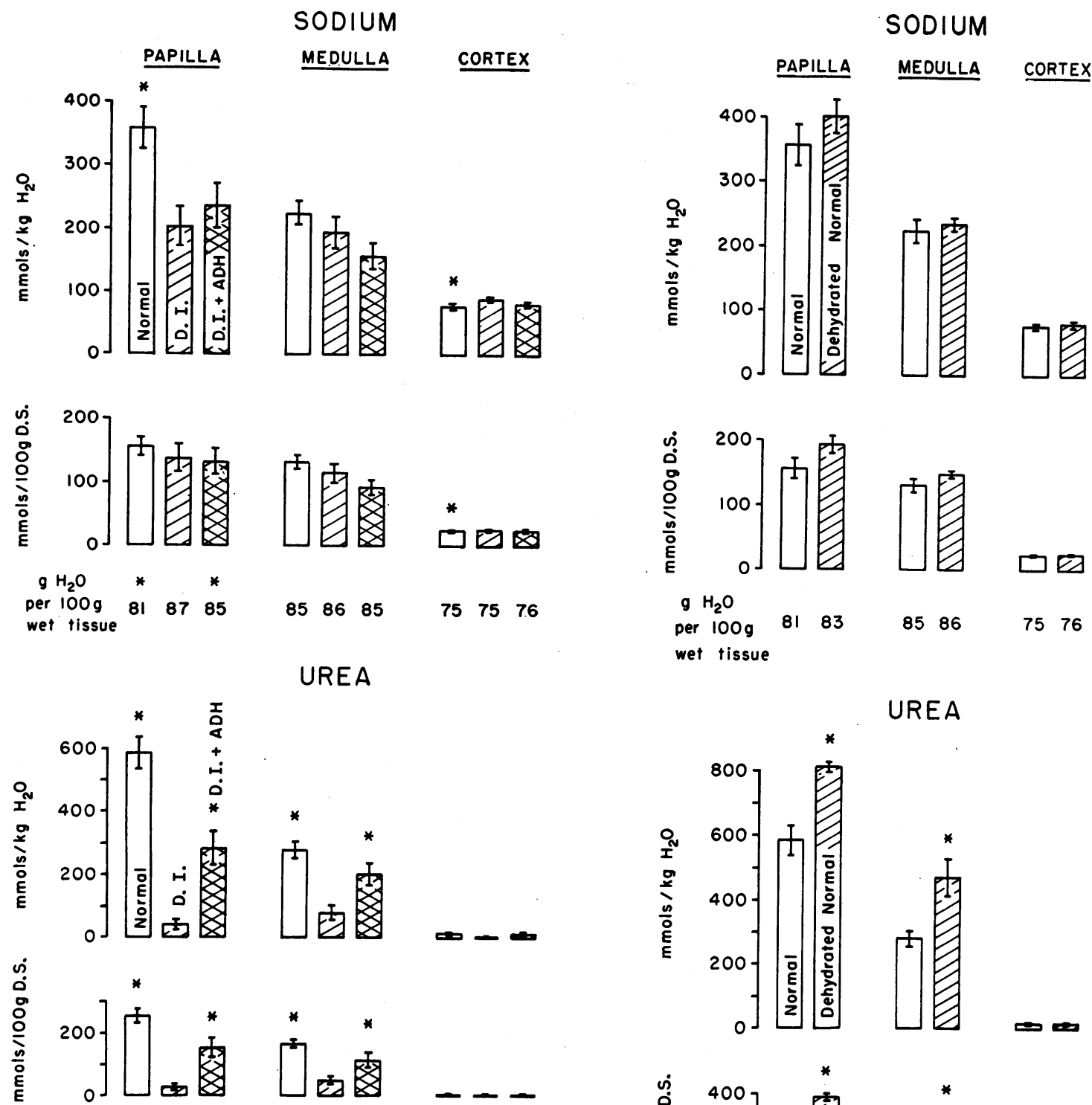

Fig. 1. Content and concentrations of Sodium, UREA, AND WATER IN PAPILLA, MEDULLA, AND CORTEX OF NORMAL RATS, RATS WITH DIABETES INSIPIDUS (D.I.) DRINKING AD LIBITUM, AND D.I. RATS THAT HAVE RECEIVED THREE DAILY IN JECTIONS OF 1.0 U VASOPRESSIN TANNATE IN oIL $(\mathrm{DI}+\mathrm{ADH})$. The columns and brackets represent the mean \pm standard error of six rats. Asterisks indicate values that are significantly different from those of D.I. rats drinking ad libitum $(p<0.05)$. D.S. $=$ dry solids.

for analysis. In treated D.I. rats, both urinary and papillary osmolalities fell between those for normal and D.I. rats.

The sodium and urea concentrations of renal tissues in the three groups are summarized in Figure 1. Sequestration of sodium in medulla and

papilla, expressed in mmoles per $100 \mathrm{~g}$ dry solids,
was not significantly less in untreated D.I. rats than
in normal ones. It was not increased in D.I. rats

papilla, expressed in mmoles per $100 \mathrm{~g}$ dry solids,
was not significantly less in untreated D.I. rats than
in normal ones. It was not increased in D.I. rats

papilla, expressed in mmoles per $100 \mathrm{~g}$ dry solids,
was not significantly less in untreated D.I. rats than
in normal ones. It was not increased in D.I. rats

Fig. 2. Content and concentrations of sodium, UREA, AND WATER IN PAPILlA, MEDULla, AND CORTEX OF NORMAL RATS AND NORMAL RATS THAT HAVE BEEN DEPRIVED OF DRINKING WATER FOR 48 HOURS. The columns and brackets represent the mean \pm standard error of six rats. Asterisks indicate values that are significantly different from normal $(p<0.05)$. 
by large doses of exogenous vasopressin. Expressed as millimoles per kilogram water, the papillary concentration of sodium was significantly higher in normal than in untreated or treated D.I. animals. Presumably this difference was due simply to the lesser content of water. The cortical concentration of sodium was significantly lower in normal animals than in the other two groups, even when expressed per $100 \mathrm{~g}$ dry solids. Thus this difference did not appear to be due to normal animals being more adequately hydrated than D.I. rats. It may have resulted from a significantly higher plasma sodium concentration in D.I. than in normal rats (15), and it is reminiscent of the finding that sodium content is greater in skeletal muscle of D.I. than of normal rats (16).

The concentrations of urea in medullary and papillary tissues contrast sharply with those of sodium. Expressed as mmoles either per $100 \mathrm{~g}$ dry solids or per $\mathrm{kg}$ water, urea concentrations were significantly higher in the presence of vasopressin than in its absence. But this apparent effect of vasopressin did not pertain for samples of renal cortex.

Dehydration of normal rats. The data are presented in Table I and Figure 2. Depriving normal rats of drinking water, but not of food, for 48 hours caused a significant fall in urine flow and rise in urinary osmolality, compared to normal rats drinking ad libitum. Content of water in renal tissues was not significantly different from normal (Figure 2), nor were the wet -weights of tissues. Total osmolality of both medulla and papilla rose significantly during dehydration when compared to normally hydrated rats. This rise was due to both sodium and urea, although principally the latter.

Dehydration of D.I. rats. The results are presented in Table I and Figure 3. During 12 hours of water deprivation, D.I. rats decreased urine flow and increased urinary osmolality significantly over D.I. rats drinking ad libitum. The cortical content of water was decreased slightly and significantly from that in normally hydrated D.I. rats, but the changes in the water content of the other renal tissues were not significant statistically (Figure 3 ). Wet weights of tissues were not significantly different in the two groups.

Total papillary osmolality was significantly greater in dehydrated than in untreated D.I. rats.
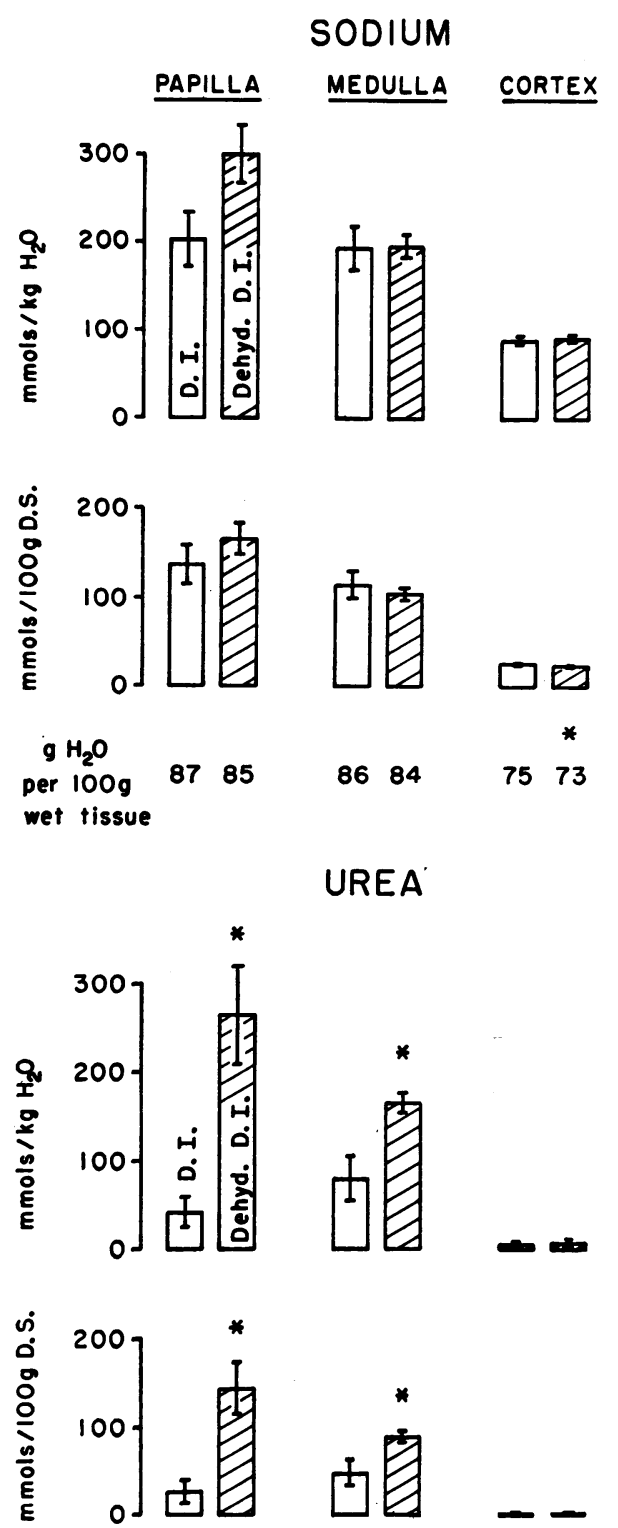

Fig. 3. Content and concentrations of Sodium, UREA, AND WATER IN PAPILla, MEDUlLA, AND CORTEX OF RATS WITH DIABETES INSIPIDUS DRINKING AD LIBITUM AND D.I. RATS THAT HAVE BEEN DEPRIVED OF DRINKING WATER FOR 12 HOURS. The columns and brackets represent the mean $\pm \mathrm{SE}$ of six rats. Asterisks indicate values that are significantly different from those of D.I. rats drinking ad libitum $(p<0.05)$.

It is perhaps even more noteworthy that 12 hours of water deprivation was as effective in raising the papillary osmolality in D.I. rats as were high doses of exogenous vasopressin. Yet urinary osmolality remained much lower in dehydrated than in treated D.I. rats. This suggests that dehydration did not 
alter the permeability to water of membranes lining the distal nephron. Medullary osmolality also rose significantly in dehydrated D.I. rats when compared to untreated D.I. rats. Figure 3 shows that the increases in medullary and papillary osmolalities were accounted for solely or principally by increased sequestration of urea but not of sodium.

One other result during dehydration of D.I. rats was particularly striking. This was the only group in which the concentration of urea in the papilla exceeded that in the urine. Although at first glance this finding may suggest active tubular reabsorption of urea, a more plausible explanation may be dilution of the urinary urea by urine formed during the early portion of the 12-hour collection period (see Discussion).

\section{Discussion}

Because in the kidney water is thought to diffuse passively in response to osmotic gradients, the concentration of solutes (expressed as millimoles per kilogram of tissue water) probably is the important physiological variable. In order to assess the actual amounts of solutes within the tissues, the content (expressed as millimoles per unit of dry solids) seems more appropriate. Saikia (8) has rightly pointed out that urea-free dry solid may be the most accurate expression. Applying this correction to our data would not change the conclusions.

Normal vs. untreated and treated D.I. rats. The rationale underlying the first series of experiments (Figure 1) was that if vasopressin slowed medullary blood flow or enhanced the reabsorption of sodium from the ascending loops of Henle, or if it did both, then the content of sodium should be greater in the medulla and papilla of normal rats than of D.I. rats. No such difference was found. Nor was the sodium content changed significantly when D.I. rats were given large amounts of vasopressin. But the medullary and papillary contents of urea were significantly higher in both normal and treated D.I. rats than in untreated D.I. animals. Since the sodium contents suggest that vasopressin does not decrease medullary blood flow, the increased sequestration of urea probably results from increased deposition into medulla and papilla in the presence of the hormone.

Total papillary osmolalities were higher in nor- mal and treated D.I. rats than in untreated D.I. rats although the change was significant statistically only in normal animals (Table I). The differences were accounted for almost completely by two factors: the significantly smaller papillary water content in normal and treated D.I. rats, which increased concentrations of all solutes, and the significantly greater content of urea. Thus, the greater interstitial medullary and papillary osmolalities that are seen in the presence of vasopressin as compared to its absence can be explained solely by the increased permeability of distal tubular and collecting duct membranes that this hormone probably induces $(8,17)$. In the presence of vasopressin more water is reabsorbed from the distal convoluted tubules. Consequently, less fluid is delivered to the collecting ducts and less water is reabsorbed from them. These events are abetted by the increased permeability of collecting ducts for urea that vasopressin brings about $(18,19)$.

At first glance this view might appear to conflict with those of others who have observed increased medullary and papillary sequestration of sodium under the influence of vasopressin $(2,4)$, and especially with the findings of Thurau, Deetjen, and Kramer (20) concerning the influence of vasopressin on medullary blood flow. Resolution of the apparent conflict may lie in important differences between animals in acute water diuresis and those with naturally occurring diabetes insipidus used in the present experiments. Thurau and co-workers showed that in water-loaded dogs medullary blood flow may have been increased by as much as $75 \%$ at the height of water diuresis. As this diuresis was interrupted by giving vasopressin, medullary blood flow gradually returned to normal over a $2 \frac{1}{2}$-hour period. It appeared to remain normal even when the ratio of urinary to papillary osmolality $\left(\mathrm{U} / \mathrm{P}_{\mathrm{osm}}\right)$ ranged between 2.0 and $4.0(20)$. These studies showed, then, that vasopressin can reverse the increase in medullary blood flow that occurs in water diuresis; they did not demonstrate depression of this blood flow below normal. This effect of vasopressin could be an indirect one and need not involve a direct action of the hormone on the vasa recta.

Levitin and associates (2), and Perlmutt (4) obtained their data on dogs during acute water diuresis and within 2 hours after beginning an infusion of vasopressin. Their conclusion seems 
correct, therefore, that the observed differences in sodium content of medulla and papilla resulted from differences in medullary blood flow. In our animals, however, water diuresis existed in the absence of an acute expansion of total body water, and it may therefore be reasonable to assume that their medullary blood flow was normal and remained so during treatment with vasopressin. Of course, Jaenike also studied water-loaded dogs, but he inferred solute concentrations in renal tissues and did not measure them directly (3). Saikia's failure to observe a significant decrease in papillary sodium content during acute water diuresis in rats may have been due to relatively mild hydration by the intraperitoneal route (8). That this method led to only moderate water diuresis is suggested by the mean osmolalities of 172 mOsm per $\mathrm{kg}$ in urine and 1,263 mOsm per $\mathrm{kg}$ in the papilla.

Dehydration of normal rats. It is well known that total osmolality of the renal papilla is higher during water deprivation than when supramaximal doses of vasopressin are given. Almost certainly this is not due to a difference between endogenous and exogenous vasopressin. Rather, it seems likely that decreases in GFR and in medullary blood flow enhance the above-postulated effects of vasopressin on the countercurrent mechanism.

Our results on normal rats deprived of drinking water for 48 hours agree with those of certain others $(2,7)$. The medullary and papillary contents of sodium tended to be greater in thirsted animals than in normal ones drinking ad libitum (Figure 2), although the change was of borderline significance $(p<0.10)$ only in the papilla. The increases in both medullary and papillary urea were much more pronounced than those of sodium.

The following plausible chain of events might explain the changes during thirsting. For unknown reasons, possibly a decrease in GFR, there is less flow of fluid in the distal nephron and more complete reabsorption of urea than during normal hydration. In addition, there may be a decrease in medullary blood flow, which promotes the sequestration of urea and of sodium. The extent of these operations probably depends not on the concentration of vasopressin in the blood, but on the degree of dehydration and on a possible species difference in tolerating dehydration. Such experimental differences might explain seemingly discrepant results (8).

Dehydration of D.I. rats. The changes in medullary and papillary composition that were induced in D.I. rats by 3 days of treatment with vasopressin were duplicated in the absence of vasopressin by dehydrating D.I. animals for 12 hours (Table I). Yet the urinary osmolality remained much lower than in treated D.I. rats, suggesting that dehydration did not alter the permeability of membranes in the distal nephron.

The results in dehydrated D.I. rats suggest the critical role of GFR and the medullary blood flow in the countercurrent mechanism. In these animals the medullary and papillary sequestration of urea was as great as in treated D.I. rats, even though membrane permeability probably did not change. The explanation may involve active tubular reabsorption $(21,22)$ or synthesis of urea (23), but it is difficult to find a reason a priori why these processes should be accelerated during short periods of dehydration. Hence it seems more plausible to invoke possible decreases in GFR and in medullary blood flow, having the consequences that were outlined in the section above. The fact that the sodium contents of medulla and papilla of thirsted D.I. rats were not significantly higher than those of untreated D.I. rats does not refute this thesis, for the increased trapping of sodium that would be expected from decreased medullary blood flow may have been countered by decreased GFR and consequent reduced delivery of sodium to the ascending loops of Henle.

Passive diffusion of urea and trapping of urea by diminished flow through the vasa recta cannot account for the papillary urea concentration exceeding that in the urine in dehydrated D.I. rats (Table I). Although this finding might reflect active tubular reabsorption or synthesis of urea, it seems more probable that the low urinary concentration of urea was due to dilution. Urine was collected during the entire 12-hour period of dehydration. Had a terminal urine sample been analyzed its concentration of urea might have equaled or exceeded that in the papilla. The failure to observe a lower urinary than papillary urea concentration in dehydrated normal rats may have several causes. First, the concentration gradient for urea from outer medulla toward papillary tip was 
undoubtedly much steeper in dehydrated normal than in dehydrated D.I. rats; hence the average papillary value did not closely approximate the concentration at the papillary tip. Secondly, the urine during the early part of the collection period in dehydrated normal rats was not nearly so dilute as that from dehydrated D.I. rats. And thirdly, the changes that accompanied dehydration occurred much more rapidly in D.I. than in normal rats. For example, D.I. rats lost about the same proportion of body weight $(10.8 \%)$ in 12 hours that normal rats lost during 48 hours of dehydration $(9.5 \%)$.

\section{Summary}

$\mathrm{Na}^{+}, \mathrm{K}^{+}, \mathrm{NH}_{4}^{+}$, urea, and water content were measured in the renal cortex, medulla, and papilla of normal rats and of rats with hereditary hypothalamic diabetes insipidus (D.I.) under various experimental conditions.

The medullary and papillary contents of sodium (mmoles per $100 \mathrm{~g}$ dry solids) were no greater in normal rats than in D.I. rats drinking ad libitum. Nor were these contents increased in D.I. rats after they had been treated for 3 days with large amounts of vasopressin. In contrast, the medullary and papillary contents of urea were significantly greater in normal animals and D.I. rats treated with vasopressin than in untreated D.I. animals.

These results suggest that vasopressin does not decrease medullary blood flow below normal or enhance the reabsorption of sodium from the loops of Henle. Rather, all the data can be explained through a sole action of vasopressin that alters the permeability to water and urea of membranes lining the tubules of the distal nephron.

The medullary and papillary contents of both sodium and urea were higher in normal rats deprived of drinking water for 48 hours than in normal rats drinking ad libitum, but the increases were of undoubted statistical significance only for urea. It is suggested that the composition of the renal medulla and papilla during thirsting depends much more on the extent of dehydration and the possibly consequent effects on glomerular filtration rate (GFR) and medullary blood flow than on changes in the concentration of endogenous vasopressin. Differences in both degree of hydration and degree of dehydration may largely ac- count for the discrepant results from various laboratories concerning the composition of renal tissues in various states of diuresis and antidiuresis.

Twelve hours of dehydration was as effective in raising the medullary and papillary osmolalities of D. I. rats as were three daily injections of vasopressin. In thirsted D.I. rats the medullary and papillary contents of sodium were not significantly different from those of D.I. rats drinking ad libitum, but the contents of urea were significantly increased by dehydration. These results emphasize the importance of mechanisms other than changes in membrane permeability (perhaps principally GFR and medullary blood flow) in the operation of the countercurrent mechanism.

\section{Acknowledgments}

I thank Mrs. Robert A. Garrity for invaluable technical help. Dr. Avery R. Harrington kindly reviewed the manuscript.

\section{References}

1. Gottschalk, C. W. Osmotic concentration and dilution of the urine. Amer. J. Med. 1964, 36, 670.

2. Levitin, H., A. Goodman, G. Pigeon, and F. H. Epstein. Composition of the renal medulla during water diuresis. J. clin. Invest. 1962, 41, 1145.

3. Jaenike, J. R. Acute effects of the administration of vasopressin during water diuresis in the dog. J. clin. Invest. 1963, 42, 161.

4. Perlmutt, J. H. Influence of hydration on renal function and medullary sodium during vasopressin infusion. Amer. J. Physiol. 1962, 202, 1098.

5. Saikia, T. C. The acute effect of vasopressin upon the composition of the rat renal cortex and medulla. Quart. J. exp. Physiol. 1965, 50, 158.

6. Valtin, H., W. H. Sawyer, and H. W. Sokol. Neurohypophysial principles in rats homozygous and heterozygous for hypothalamic diabetes insipidus (Brattleboro strain). Endocrinology 1965, 77, 701.

7. Ruiz-Guiñazú, A., E. E. Arrizurieta, and L. Yelinek. Electrolyte, water, and urea content in dog kidneys in different states of diuresis. Amer. J. Physiol. 1964, 206, 725.

8. Saikia, T. C. Composition of the renal cortex and medulla of rats during water diuresis and antidiuresis. Quart. J. exp. Physiol. 1965, 50, 146.

9. Del Greco, F., and H. E. De Wardener. The effect on urine osmolarity of a transient reduction in glomerular filtration rate and solute output during a "water" diuresis. J. Physiol. (Lond.) 1956, $131,307$. 
10. Berliner, R. W., and D. G. Davidson. Production of hypertonic urine in the absence of pituitary antidiuretic hormone. J. clin. Invest. 1957, 36, 1416.

11. Valtin, H. Unpublished data.

12. Conway, E. J. Microdiffusion Analysis and Volumetric Error. New York, Macmillan, 1958, chap. IX and XVII.

13. Hill, A. B. Principles of Medical Statistics, 7th ed. New York, Oxford University Press, 1961, pp. 146-149.

14. Harrington, A. R., and H. Valtin. Vasopressin effect on urinary concentration in rats with hereditary hypothalamic diabetes insipidus (Brattleboro strain). Proc. Soc. exp. Biol. (N. Y.) 1965, 118, 448.

15. Valtin, H., and H. A. Schroeder. Familial hypothalamic diabetes insipidus in rats (Brattleboro strain). Amer. J. Physiol. 1964, 206, 425.

16. Friedman, S. M., and C. L. Friedman. Salt and water distribution in hereditary and in induced hypothalamic diabetes insipidus in the rat. $\mathrm{Ca}$ nadian Journal of Physiology and Pharmacology 1965, 43, 699.

17. Jaenike, J. R. The relative rates of urea and water permeation in the distal nephron of the intact kidney. J. clin. Invest. 1964, 43, 45.

18. Jaenike, J. R. The influence of vasopressin on the permeability of the mammalian collecting duct to urea. J. clin. Invest. 1961, 40, 144.

19. Gardner, K. D., Jr., and R. H. Maffly. An in vitro demonstration of increased collecting tubular permeability to urea in the presence of vasopressin. J. clin. Invest. 1964, 43, 1968.

20. Thurau, K., P. Deetjen, and K. Kramer. Hämodynamik des Nierenmarks. II. Wechselbeziehung zwischen vasculärem und tubulärem Gegenstromsystem bei arteriellen Drucksteigerungen, Wasserdiurese und osmotischer Diurese. Pflügers Arch. ges. Physiol. 1960, 270, 270.

21. Truniger, B., and B. Schmidt-Nielsen. Intrarenal distribution of urea and related compounds: effects of nitrogen intake. Amer. J. Physiol. 1964, 207, 971.

22. Lassiter, W. E., M. Mylle, and C. W. Gottschalk. Urea-C-14 concentration in vasa recta plasma and collecting duct urine of weanling rats (abstract). Fed. Proc. 1965, 24, 582.

23. Kleinman, L. I., and E. P. Radford, Jr. Urea synthesis by rat kidney (abstract). Physiologist 1964, $7,179$. 